\title{
Tackling myths of common prescribing patterns in schizophrenia amongst Egyptian psychiatrists
}

\author{
Samir Abolmagd ${ }^{1}$, Dina Aly El-Gabry ${ }^{2 *}$, Hussien Elkholy ${ }^{2}$ and Karim Abdel Aziz ${ }^{3}$
}

\begin{abstract}
Background: There is limited data related to how psychiatrists actually choose amongst different medications, especially in Egypt. Our aim was to survey a sample of psychiatrists regarding common patterns of antipsychotic prescribing practices and review how these vary from the evidence-based. We conducted a qualitative, crosssectional survey of 124 psychiatrists of different grades from hospitals across Cairo, Egypt. Questions were asked to elicit attitudes towards common antipsychotic prescribing practices and the use of treatment guidelines in schizophrenia.

Results: A total 77.4\% participants said they would prescribe atypical antipsychotics as first-line treatment if cost were not an issue, $42.7 \%$ said they commonly add anticholinergics from the start with antipsychotics, 50\% said they would maintain patients on anticholinergics for as long as they were receiving antipsychotics, $93.5 \%$ said they commonly or in some situations combine typical depot antipsychotics with oral atypical antipsychotics, $88.7 \%$ said they commonly or in some situations use antipsychotics in small doses for sedation, and $55.6 \%$ sometimes add a mood stabilizer to enhance the effect of antipsychotic drugs. Using logistic regression, physician grade significantly predicted whether participants commonly add anticholinergic medication from the start with antipsychotics $(p=$ 0.001). Age and gender significantly predicted whether participants sometimes add a mood stabilizer to enhance the effect of antipsychotics $(p<0.05)$.

Conclusions: We demonstrated that several antipsychotic prescribing practices were not evidence-based, yet appeared to be prevalent in a large proportion of participants. A number of demographic and psychiatrist-related factors predicted certain prescribing patterns.
\end{abstract}

Keywords: Schizophrenia, Antipsychotic, Prescribing, Treatment guidelines, Egypt

\section{Background}

Since the emergence of antipsychotics, many expert recommendations and guidelines on the type and the amount of antipsychotic medication to prescribe in schizophrenia have been published to guide physician decision-making [1], yet it seems that prescribing antipsychotic medication is a complex and multifactorial

\footnotetext{
* Correspondence: dinaelgabry@yahoo.com

${ }^{2}$ Okasha Institute of Psychiatry, Neuropsychiatry Department, Ain Shams

University, Abbasiya, Cairo 1156, Egypt

Full list of author information is available at the end of the article
}

process subject to a variety of influences at patient, provider, and system levels [2].

Although many clinical practice guidelines for schizophrenia have been published by many countries and organizations, there have usually been discrepancies between the guideline statements and prescription patterns in clinical practice [3-7] with variations in antipsychotic prescribing reported worldwide in the USA [8-11], Korea [3], UK [12, 13], Canada [14], India [15], and the Arab World [16]. These variations include the prevalence of antipsychotics polypharmacy compared to monotherapy, typical versus atypical antipsychotics,

\section{Springer Open}

(๑) The Author(s). 2020 Open Access This article is licensed under a Creative Commons Attribution 4.0 International License, which permits use, sharing, adaptation, distribution and reproduction in any medium or format, as long as you give appropriate credit to the original author(s) and the source, provide a link to the Creative Commons licence, and indicate if changes were made. The images or other third party material in this article are included in the article's Creative Commons licence, unless indicated otherwise in a credit line to the material. If material is not included in the article's Creative Commons licence and your intended use is not permitted by statutory regulation or exceeds the permitted use, you will need to obtain permission directly from the copyright holder. To view a copy of this licence, visit http://creativecommons.org/licenses/by/4.0/. 
preference of high-dose antipsychotics or depot antipsychotics, and anticholinergic co-prescribing [17].

A number of studies have examined the impact of patient characteristics on antipsychotic prescribing variations, such as demographic and clinical characteristics as race [6], symptom severity [18], duration of illness [19], or drug-related factors such as the availability and cost in different healthcare settings, the introduction of atypical antipsychotics with improved adverse effect profile, and efficacy or physician-related factors [7] such as order of introduction, ease of use, prescribers' idiosyncratic beliefs, marketing efforts [20], different level of awareness and recognition due to cultural variances, insufficient education regarding the etiology, and management of psychiatric disorders or simply because of differences in diagnosis [21].

The divergence of clinical practices from evidencebased guidelines identifies pressing research questions raised by these variations [20] and leads us to wonder about factors affecting prescribing practices, and why guidelines are followed in some settings but not to others [22].

Surprisingly, to the best of our knowledge, there is limited data related to psychiatrists' decision-making on drug selection and on how psychiatrists actually choose amongst different medications [23], especially in the Middle East in general and Egypt in particular. The limited research done so far points to the fact that current clinical practice in the Middle East differs from clinical recommendations [24].

Lately, this variation in practice has gained attention, partly because of the huge expenditures on antipsychotic medications [20] which is relevant to a country with economic constraints like Egypt. Moreover, it has been suggested that inadequate prescribing is a cause of unnecessarily high relapse rates in patients with schizophrenia [25]. Inappropriate prescribing may not meet patients' needs, and this in turn may contribute to negative attitudes towards treatment and the service provider [26].

Despite a high rate of antipsychotic polypharmacy prescribing in Egypt of 72.9\% [27], only one previous study in Egypt has tried to investigate the antipsychotic prescribing attitudes of psychiatrists and their characteristics. This showed that a deep understanding of the content of clinical algorithms for guidelines was limited and did not exceed $37.5 \%$ of the psychiatrists surveyed [28]. This raises concerns about some of the prescribing practices and attitudes amongst Egyptian psychiatrists which may not be supported by guidelines. Therefore, the aim of this study was to conduct a qualitative survey in a sample of Egyptian psychiatrists regarding common patterns of antipsychotic prescribing practices, and reviewing how these practices vary from the evidencebase for antipsychotic prescribing. We hypothesized that there would be a variation between common antipsychotic prescribing practices and the evidence-base for them.

\section{Methods \\ Participants}

We conducted a qualitative, cross-sectional survey of 124 male and female psychiatrists of different grades from 6 universities and public and private psychiatric hospitals from across Cairo, Egypt. These 6 hospitals were the Cairo University Hospital, Ain Shams University Hospital, Abbasiya Psychiatric Hospital, Maadi Military Hospital, Azhar University Hospital, and Okasha Psychiatric Hospital. The inclusion criteria were that participants must be qualified medical practitioners, currently working in psychiatry, and have experience in working and prescribing for patients with schizophrenia.

\section{Tools}

Participants were asked to fill out a paper questionnaire designed by the authors. They provided information about their age, gender, current grade, and years of clinical experience in psychiatry and the highest medical qualifications. They then answered a series of 12 questions designed to elicit attitudes towards common antipsychotic prescribing practices and the use of treatment guidelines in schizophrenia. These questions were about the participant's starting choice of antipsychotic medication in schizophrenia, attitude to cost considerations, attitude to dosing, attitude to combining antipsychotics, use of clozapine, use of anticholinergic medication, use of mood stabilizers, and use of antipsychotics for sedation and following treatment guidelines. A number of choices were given for each question, and participants were asked to choose the answer that most closely reflected their prescribing practice.

\section{Procedures}

Ethical approval for the study was granted by the Ain Shams University Faculty of Medicine Ethical Committee. A local investigator for each site distributed and retrieved the questionnaires, which were then sent to the principal investigator for data extraction and analysis. Each questionnaire included a page detailing the nature and purpose of the study. The purpose of the questionnaire was explained to each participant and informed consent obtained. Data was collected anonymously between August 2015 and February 2017 with participation being entirely voluntary.

\section{Statistical analysis}

Data was recorded and analyzed using the statistical package of social sciences SPSS for Windows, Version 24.0 (2016). All calculations were performed at 95\% 
confidence intervals, 0.80 power of the study, and alpha error of 0.05 . The results were tabulated, grouped, and statistically analyzed using the following tests: mean and standard deviation (SD) for parametric numerical (quantitative) data, frequency, and percentage for nonnumerical (qualitative) data. Logistic regression analysis was used to measure the effect of factors that affect the occurrence of selected responses with high frequency. A $p$ value of $<0.05$ was considered statistically significant.

\section{Results}

\section{Psychiatrists' characteristics}

Of the 124 participants in the study, 63 subjects were male $(53.8 \%)$ and 54 subjects were female $(46.2 \%)$. The mean age of the sample was 32.81 years $(S D=7.36)$. Table 1 summarizes the sample characteristics also as regards current grade, years of experience, and the highest qualifications in psychiatry.

\section{Patterns of antipsychotic prescribing}

Table 2 shows the distribution of responses to each question about common prescribing practices for patients with schizophrenia. This shows a high rate of frequency of responses that are not evidence-based from the current literature or from guidelines. A total of 96 (77.4\%) participants said they would prescribe atypical antipsychotics as first-line treatment if cost were not an

Table 1 Characteristics of the sample

\begin{tabular}{|c|c|c|}
\hline & Mean & SD \\
\hline Age $(N=113$, missing $=11)$ & 32.81 & 7.36 \\
\hline Gender $(N=117$, missing $=7)$ & $N=117$ & $\%$ \\
\hline Male & 63 & 53.8 \\
\hline Female & 54 & 46.2 \\
\hline Current grade $(N=120$, missing $=4)$ & $N=120$ & $\%$ \\
\hline Resident & 49 & 39.5 \\
\hline Specialist & 54 & 43.5 \\
\hline Consultant & 15 & 12.1 \\
\hline \multirow[t]{2}{*}{ Professor } & 2 & 1.6 \\
\hline & Mean & SD \\
\hline Years of experience $(N=108$, missing $=16)$ & 7.24 & 7.39 \\
\hline Highest qualification $(N=118$, missing $=6)$ & $N=118$ & $\%$ \\
\hline MBBCh & 33 & 26.6 \\
\hline Diploma & 19 & 15.3 \\
\hline Masters & 45 & 36.3 \\
\hline $\mathrm{MD} / \mathrm{PhD}$ & 13 & 10.5 \\
\hline MRCPsych/ FRCPsych & 3 & 2.4 \\
\hline Egyptian board & 2 & 1.6 \\
\hline Arab board & 3 & 2.4 \\
\hline American board/others & 0 & 0 \\
\hline
\end{tabular}

issue, 53 (42.7\%) said they commonly add anticholinergic medication from the start with antipsychotics, $62(50 \%)$ said they would maintain patients on anticholinergic medication for as long as they were receiving antipsychotics, 116 (93.5\%) said they commonly or in some situations combine a typical depot antipsychotic with an oral atypical antipsychotic, $110(88.7 \%)$ said they commonly or in some situations use an antipsychotic in a small dose for sedation, and 69 (55.6\%) sometimes add a mood stabilizer to enhance the effect of antipsychotic drugs.

\section{Demographic and psychiatrists characteristics predicting high-frequency responses}

Logistic regression analysis was carried out for demographic and psychiatrists-related factors to evaluate whether these factors affect the occurrence of high-frequency responses that are not evidence-based (Table 3). The regression coefficient shows the effect of each variable after controlling the effect of other variables in the model. The current grade was a significant predictor for the response that participants commonly add anticholinergic medication from the start with antipsychotics $(p=0.001)$. Age and gender were significant predictors for the response that participants sometimes add a mood stabilizer to enhance the effect of antipsychotic drugs $(p<0.05)$.

\section{Discussion}

This study included 124 psychiatrists from the different public, private, and university hospitals in Egypt. Taking into consideration that the total number of psychiatrists registered in Egypt is around 1100 psychiatrists (Egyptian Psychiatrists Association, personal communication, 2018) with many these working outside the country [29], we could conclude that our results reflect an insight into the common prescribing attitudes amongst Egyptian psychiatrists and might be considered an initial step to generate national-level data to understand the prescription patterns of psychiatrists practicing in Egypt.

\section{Atypical versus typical antipsychotics}

The controversy about the marketing claims of the atypical antipsychotics superior efficacy and fewer side effects compared to typicals [30] started around the year 2000 [31] followed by the two effectiveness trials (CATIE and CUtLASS) comparing atypicals and typicals and which provided confirmation that there was no clear difference between both groups either in effectiveness or quality of life [32, 33]. This is reflected in most current international guidelines (e.g., NICE guidelines, Maudsley Prescribing Guidelines) which recommend that no one antipsychotic is preferred over another and that prescribing is based mainly on patient choice and 
Table 2 Frequency of distribution of responses to questions about prescribing practices for patients with schizophrenia

\begin{tabular}{lcc}
\hline & $\mathbf{N = 1 2 4}$ & $\%$ \\
\hline Q1 When first prescribing an antipsychotic drug to a patient with schizophrenia, most of the time your choice is primarily guided by: & 23 & 18.5 \\
a- Your own experience & 40 & 32.3 \\
b- Guidelines & 11 & 8.9 \\
c- Cost of the drug & 0 & 0 \\
d- Patient choice & 49 & 39.5 \\
e- Patients clinical profile & 1 & 0.8
\end{tabular}

Q2 If cost was not an issue, what would be your preferred first line antipsychotic of choice for a patient with schizophrenia:

a- Oral typical antipsychotic drug

b- Oral atypical antipsychotic drug

c- Combination of oral antipsychotics (eg typical+atypical, 2 typicals, 2 atypicals)

d- Depot antipsychotic-typical/atypical (circle one if preferred)

f- Oral+depot

g- Clozapine

h- No particular preference.

g- Other

Q3 When prescribing a first line antipsychotic for a patient with schizophrenia, your starting dose is:

a- The minimum effective antipsychotic dose of the drug.

b- A moderate antipsychotic dose of the drug.

c- The maximum antipsychotic dose of the drug.

Q4 Which of the following most closely reflects your practice in schizophrenia?

a- I never combine two or more antipsychotic drugs (eg typical+atypical, 2 typicals, 2 atypicals).

b- I commonly combine two or more antipsychotic drugs.

c- In some situations, I can combine two or more antipsychotic drugs.

d- Not stated

Q5 Which of the following most closely reflects your practice in schizophrenia?

a-I never prescribe antipsychotic medications above the maximum dose.

b- I commonly prescribe antipsychotic medications above the maximum dose.

c- In some situations, I prescribe antipsychotic medications above the maximum dose.

d- Other

Q6 In your practice, when do you most commonly consider prescribing clozapine in schizophrenia:

a- Never

b- First line

c- Second line

d- Third line

e- Other

Q7 Which of the following most closely reflects your practice?

a- When prescribing antipsychotic drugs, I commonly add an anticholinergic from the start

b- When prescribing antipsychotic drugs, I never add an anticholinergic from the start

c- In some situations, I will add an anticholinergic from the start

d- Other/not stated

Q8 Which of the following most closely reflects your practice? 
Table 2 Frequency of distribution of responses to questions about prescribing practices for patients with schizophrenia (Continued)

\begin{tabular}{|c|c|c|}
\hline & $N=124$ & $\%$ \\
\hline \multicolumn{3}{|l|}{ receiving an antipsychotic } \\
\hline $\begin{array}{l}\text { b- If I start an anticholinergic, I mostly discontinue them after several weeks while continuing } \\
\text { to maintain the patient on an antipsychotic. }\end{array}$ & 58 & 46.8 \\
\hline c- Other/not stated & 4 & 3.2 \\
\hline \multicolumn{3}{|l|}{ Q9 Which of the following most closely reflects your practice? } \\
\hline a- I never combine typical depot antipsychotic with an oral atypical antipsychotic & 6 & 4.8 \\
\hline b- I commonly combine typical depot antipsychotic with an oral atypical antipsychotic. & 47 & 37.9 \\
\hline c- In some situations I combine typical depot antipsychotic with an oral atypical antipsychotic. & 69 & 55.6 \\
\hline d- Other/not stated & 2 & 1.6 \\
\hline \multicolumn{3}{|l|}{ Q10 Which of the following most closely reflects your practice? } \\
\hline a- I never prescribe an antipsychotic in a small dose for sedation. & 12 & 9.7 \\
\hline b- I commonly prescribe an antipsychotic in a small dose for sedation. & 55 & 44.4 \\
\hline c- I sometimes prescribe an antipsychotic in a small dose for sedation. & 55 & 44.4 \\
\hline other/not stated & 2 & 1.6 \\
\hline \multicolumn{3}{|l|}{ Q11 Do you add a mood stabilizer to enhance the effect of the antipsychotics? } \\
\hline a- I never add a mood stabilizer to enhance the effect of antipsychotic drugs & 39 & 31.5 \\
\hline b- I commonly add a mood stabilizer to enhance the effect of antipsychotic drugs & 13 & 10.5 \\
\hline c- I sometimes add a mood stabilizer to enhance the effect of antipsychotic drugs & 69 & 55.6 \\
\hline d- Other/not stated & 3 & 2.4 \\
\hline \multicolumn{3}{|l|}{ Q12 Do you refer to any specific treatment guidelines for your prescribing? } \\
\hline a- No & 44 & 35.5 \\
\hline b- Yes & 73 & 58.9 \\
\hline c- Other/not stated & 7 & 5.6 \\
\hline
\end{tabular}

medication tolerability rather than specifically recommending a class or individual antipsychotic as a first-line $[34,35]$.

Yet, our study showed that still $77 \%$ of psychiatrists preferred prescribing second-generation antipsychotics as first-line, if the cost was not an issue. This is in line with previous results in other developing countries as in Pakistan and India which showed that risperidone and olanzapine are the two most commonly prescribed antipsychotics by $88.69 \%$ of psychiatrists in India with haloperidol being the third most commonly preferred antipsychotic [36]. Furthermore, a survey by Varghese [37] pointed out that amongst recently qualified postgraduate psychiatrists, there were few who were comfortable with using typical antipsychotics. On the other hand, a survey Pakistan reported that $81 \%$ of psychiatrists responded by choosing an atypical if they were hypothetically ill themselves [38]. The fact that although some of the newer drugs are associated with lower rates of extrapyramidal side effects (EPSE)/tardive dyskinesia, yet they are also linked to different and equally severe side-effects such as diabetes, with some of the newer drugs having similar rates of EPSE to the older drugs [30], and the absence of routine lab monitoring for metabolic side effects in Egyptian public hospitals raises some concerns about the appropriateness of this prescribing attitude.

\section{Prophylactic anticholinergic drugs}

Approximately half of our subjects declared that on prescribing antipsychotic drugs, they commonly add an anticholinergic from the start and would maintain patients on them as long as they were receiving an antipsychotic. Using logistic regression, the current grade significantly predicted prescribing of anticholinergics from the start with antipsychotics. This might be reflective of the current practice that during psychiatric training, junior doctors routinely add an anticholinergic when prescribing antipsychotics, in order to prevent some of the associated movement side-effects. This is in line with a previous study in Bahrain [17] which showed that anticholinergics are extensively co-prescribed along with both typical and atypical antipsychotics, a finding seen in other studies [39-42].

This might be related to various ideological beliefs and possible cultural and institutional practices [43]. One of these factors is the idea of routinely prescribing an anticholinergic even in absence of extrapyramidal side 
Table 3 Logistic regression analysis showing factors predicting responses with high frequency

\begin{tabular}{|c|c|c|}
\hline Q2b & B & $p$ \\
\hline Age & 0.015 & 0.549 \\
\hline gender & 0.240 & 0.581 \\
\hline Years of Experience & -0.054 & 0.123 \\
\hline current grade & 0.163 & 0.572 \\
\hline highest qualification & 0.009 & 0.937 \\
\hline Q7a & B & $p$ \\
\hline Age & -0.012 & 0.598 \\
\hline gender & -0.368 & 0.338 \\
\hline Years of Experience & 0.018 & 0.620 \\
\hline current grade & -1.341 & $0.001^{*}$ \\
\hline highest qualification & 0.298 & 0.058 \\
\hline Q8a & B & $p$ \\
\hline Age & -0.020 & 0.325 \\
\hline gender & -0.007 & 0.985 \\
\hline Years of Experience & 0.041 & 0.195 \\
\hline current grade & -0.008 & 0.970 \\
\hline highest qualification & -0.046 & 0.624 \\
\hline Q9b & B & $p$ \\
\hline Age & -0.001 & 0.966 \\
\hline gender & 0.440 & 0.221 \\
\hline Years of Experience & 0.025 & 0.424 \\
\hline current grade & -0.159 & 0.509 \\
\hline highest qualification & -0.044 & 0.659 \\
\hline Q10b & B & $p$ \\
\hline Age & -0.033 & 0.123 \\
\hline gender & -0.118 & 0.739 \\
\hline Years of Experience & 0.037 & 0.233 \\
\hline current grade & -0.038 & 0.864 \\
\hline highest qualification & 0.075 & 0.425 \\
\hline Q11c & B & $p$ \\
\hline Age & 0.061 & $0.008^{*}$ \\
\hline gender & 0.741 & $0.045^{*}$ \\
\hline Years of Experience & -0.014 & 0.678 \\
\hline current grade & -0.011 & 0.962 \\
\hline highest qualification & -0.044 & 0.642 \\
\hline
\end{tabular}

$B$ regression coefficient, $p p$ value

"Statistically significant

effects (EPSE) to prevent any possible extrapyramidal symptoms. This commonly occurs in Egypt, especially in the private sector outpatient setting, where prophylactic anticholinergics are prescribed for fear that if any EPSEs occur, then patients would seek out another psychiatrist. Anticholinergics are also added to some atypical antipsychotics such as risperidone where extrapyramidal side effects appear to occur in $60 \%$ to $70 \%$ if the patients are taking doses greater than $6 \mathrm{mg} /$ day [44]. Another reason could be the widely held belief amongst Egyptian psychiatrists that the use of multiple drugs with different pharmacological actions is more effective, such as the common practice of adding anticholinergic to clozapine to mitigate clozapine-induced hypersalivation [45]. This therapeutic dilemma has been addressed by Gjerden et al. [46] who viewed that anticholinergic use appears to be superfluous for at least one third of patients, and their use exceeded the incidence of EPSE [47], with chronic administration of anticholinergics contributing to the occurrence of tardive dyskinesia [48].

On the other hand, anticholinergics should be used prudently because in addition to their well-known peripheral side-effects, they may worsen positive symptoms, appear to partially ameliorate negative symptoms, and are associated with impaired cognitive functioning [49], especially in the elderly [50], which may add to the cognitive impairment caused by the illness itself and the use of antipsychotics [51], in addition to the potential for abuse [52].

\section{Use of antipsychotics for sedation}

Other questionable practices include the prescribing of antipsychotics for sedation where most participants in our study reported using an antipsychotic in a small dose as a sedative drug. Unfortunately, this is practiced on a large scale amongst Egyptian psychiatrists where one multicentre study [24] showed that clozapine was frequently used in Egypt in comparison to other Arab Countries and especially in lower doses for sedation. It seems questionable at best and unethical at worst to subject patients to the hazards of the side effects (e.g., agranulocytosis, metabolic syndrome) of such a potent drug that is indicated only for use in resistant cases, just for the sake of sedation.

\section{Combining typical antipsychotic depots with atypical oral antipsychotics}

Interestingly, approximately about one third (37.9\%) of our subjects reported that they commonly combine typical depot antipsychotics with an oral atypical one and nearly half (55.6\%) reported combining typical depot antipsychotics with an oral atypical antipsychotic in some situations. These findings are consistent with other studies and probably stem from the common practice of adding a depot medication in cases of non-compliance to the already given drug. Later, doctors and patients may have unrealistic expectations of benefits of such combinations and may be reluctant to stop the partially effective drug [13]. However, combining typical depot with atypical oral or vice versa, points to the confusion that some doctors have about the mechanism of action 
of these drugs, as co-prescribing typicals with atypicals will nullify potential benefits of the atypical drug.

This pattern of prescribing may also be explained by the availability and affordability of antipsychotics. This may differ according to whether patients are seen in the private sector or public sector, where atypical depot medication is very expensive and so are rarely prescribed in public hospitals [24], leaving psychiatrists with little option to using typical depot medications if patients need a long-acting drug.

\section{Adding a mood stabilizer to enhance the effect of antipsychotics}

More than half of our subjects responded that they sometimes add a mood stabilizer to the prescribed antipsychotic. This is in line with evidence from the literature that shows that there is a total increase in the use of mood stabilizers in general (carbamazepine, lamotrigine, pregabalin, topiramate) and valproate in particular, for patients with schizophrenia despite there being limited evidence for their efficacy, safety, and regulatory approval [53]. Their use may stem from a desire to control impulsivity and aggression in some patients [54] or to control associated affective symptoms or for use in treatment-resistant cases. However, their effect on core psychotic features remains inconclusive [55-57].

\section{Limitations}

Owing to its qualitative cross-sectional nature, our study should be considered primarily as an exploratory and distributive study. It is limited by the subjectivity of the questionnaire, which measures attitudes and not necessarily behavior. Ideally, we would have recruited a representative sample of patients into our study who are being treated by psychiatrists who are solely responsible for decisions about their medication and treatment to explore if there is a dissonance between attitude to prescribing and their practice. However, this was not possible owing to the hierarchical system especially in the educational institute in Egypt, where more than one psychiatrist are usually involved in treatment decisionmaking.

\section{Conclusions}

Our study demonstrated that while attitudes to many prescribing practices for the majority of psychiatrists in this sample were reasonable and evidence-based, some of them were not, yet was prevalent in a large percentage of participants. Future work is required to further understand factors affecting psychiatrists prescribing attitudes in Egypt and if there is clear clinical justification for practices that may vary from international guidelines. It may also point to a need to consider developing local guidelines that address the circumstances of patients and psychiatrists in Egypt and take into consideration their social and cultural circumstances.

\section{Abbreviations}

SPSS: Statistical Package for the Social Science; CATIE: Clinical Antipsychotic Trials of Intervention Effectiveness; CUtLASS: Cost Utility of the Latest Antipsychotic Drugs in Schizophrenia Study; NICE: National Institute of Clinical Excellence; EPSE: Extrapyramidal side effects

\section{Acknowledgements}

We wish to thank the subjects and volunteers who took part in this study.

Authors' contributions

All authors contributed to the conception and design of the study. SA and $\mathrm{HE}$ contributed to the data collection and editing of the manuscript. DAE contributed to the data collection and write up of the manuscript. KAA contributed to the analysis of the data and editing of the manuscript. The authors read and approved the final manuscript.

Funding

This project was self-funded.

Availability of data and materials

Available upon request.

Ethics approval and consent to participate

Ethical approval for the study was granted by the Ain Shams University Faculty of Medicine Ethical Committee. Informed consent was obtained for each participant.

\section{Consent for publication}

All authors approved the final manuscript for publication.

\section{Competing interests}

The authors declare no conflict of interest.

\section{Author details}

${ }^{1}$ Department of Psychiatry, Cairo University, Kasr Al Ainy Street, Cairo 11562, Egypt. ${ }^{2}$ Okasha Institute of Psychiatry, Neuropsychiatry Department, Ain Shams University, Abbasiya, Cairo 1156, Egypt. ${ }^{3}$ Department of Psychiatry, College of Medicine and Health Sciences, United Arab Emirates University, PO Box 17666, Al-Ain, United Arab Emirates.

Received: 8 September 2020 Accepted: 14 September 2020 Published online: 01 December 2020

\section{References}

1. McEvory JP, Scheifler PL, Frances A (1999) The expert consensus guidelines series: treatment of schizophrenia. J Clin Psychiatry 60:4-80

2. Davis PB, Yee RL, Millar J (1994) Accounting for medical variation: the case of prescribing activity in a New Zealand general practice sample. Soc Sci Med 39:367-374

3. Park S-C, Lee M-S, Kang S-G, Lee S-H (2014) Patterns of antipsychotic prescription to patients with schizophrenia in Korea: results from the Health Insurance Review \& Assessment Service-National Patient Sample. J Korean Med Sci 29(5):719-728

4. Chen RS, Nadkarni PM, Levin FL, Miller PL, Erdos J, Rosenheck RA (2000) Using a computer database to monitor compliance with pharmacotherapeutic guidelines for Schizophrenia. Psychiatr Serv 51:791-794

5. Owen RR, Thrush CR, Kirchner JE, Booth BM (2000) Performance measurement for schizophrenia: adherence to guidelines for antipsychotic dose. Int J Qual Health Care 12:475-482

6. Lehman AF, Steinwachs DM (1998) Pattern of usual care for schizophrenia: initial results from the Schizophrenia Patient outcomes Research Team (PORT) client survey. Schizophr Bull 24:11-20

7. Young AS, Sullivan G, Burnam MA, Brook RH (1998) Measuring the quality of outpatient treatment for Schizophrenia. Arch Gen Psychiatry 55:611-617

8. Clark RE, Bartels SJ, Mellman TA, Peacock WJ (2002) Recent trends in antipsychotic combination therapy of schizophrenia and schizoaffective disorder: implications for State mental health policy. Schizophr Bull 28(l):75 $-84,2002$ 
9. Covell NH, Jackson CT, Evans AC, Essock SM (2002) Antipsychotic prescribing practices in Connecticut's public mental health system: rates of changing medications and prescribing styles. Schizophr Bull 28(1):17-29

10. Pappadopulos E, Jensen PS, Schur SB, Rube D (2002) "Real world" atypical antipsychotic prescribing practices in public child and adolescent inpatient settings. Schizophr Bull 28(1):111-121

11. Weissman E (2002) Antipsychotic prescribing practices in the Veterans Healthcare Administration-New York metropolitan region. Schizophr Bull 28(l):31-42

12. Howes OD, Vergunst F, Gee S, Mc Guire P, Kapur S, Taylor D (2012) Adherence to treatment guidelines in clinical practice: study of antipsychotic treatment prior to clozapine initiation. Br J Psychiatry 201:481-485

13. Paton C, Lelliott P, Harrington M, Okacha C, Sensky T, Duffet R (2003) Patterns of antipsychotics and anticholinergic prescribing for hospital inpatient. J Psychopharmacol 17(2):223-229

14. Olajide A, Mansfield M, Olubankole O, Udoka O (2016) Psychotropic drug prescription practice in psychiatric inpatients in Saskatchewan, Canada. J Neuropsychopharmacol Mental Health 1(4):114

15. Ghosh S, Bhattacharyya S, Dalai CK (2013) Antipsychotic prescribing pattern in a tertiary Care Hospital Of Eastern India. J Drug Deliv Ther 3(4):38-42

16. Amr M, Amin T, Al-Rhaddad D et al (2013) Antipsychotic prescribing pattern in Arab patients with schizophrenia. Eur Psychiatry 28(1):1

17. Khaja K, Al-Haddad M, Sequeira R, Al-Offi AR (2012) Antipsychotic and anticholinergic drug prescribing pattern in psychiatry: extent of evidencebased practice in Bahrain. Pharmacol Pharm 3(4):409-416

18. Peralta V, Cuesta MJ, Caro F, Martinez-Larrea A (1994) Neuroleptic dose and schizophrenic symptoms. A survey of prescribing practices. Acta Psychiatr Scand 90(5):354-357

19. Cuffel BJ, Fischer EP, Owen RR Jr, Smith GR Jr (1997) An instrument for measurement of outcomes of care for schizophrenia. Issues in development and implementation. Eval Health Prof 20(1):96-108

20. Essock SM (2002) Antipsychotic prescribing practices. Schizophr Bull 28(1):1-4

21. Mukesh R, Mohanta GP, Lokesh U (2010) Study of prescription practice for antipsychotic drugs by psychiatrists- a survey. Indian J Pharmacol Pract 3(2): 23-27

22. Baandrup L, Gasse C, Jensen VD, Glenthoj BY, Nordentojlt M, Lublin H (2010) Antipsychotic polypharmacy and risk of death from natural causes in patients with schizophrenia: a population-based nested case-control study. J Clin Psychiatry 71(2):103-108

23. Latas M, Stojkovic T, Ralic T, Millovanovic S, Jasovic-Gasic M (2012) Psychiatrists Psychotropic Drug Prescription Preferences for themselves or their family members. Psychiatr Danub 24(2):182-187

24. Alkhadhari S, Al Zain N, Darwish T, Khan S, Okasha T, Ramy H (2015) Use of second-generation antipsychotics in the acute inpatient management of schizophrenia in the Middle East. Neuropsychiatr Dis Treat 11:915-924

25. Kissling W (1994) Compliance, quality assurance and standards for relapse prevention in schizophrenia. Acta Psychiatr Scand Suppl 382:16-24

26. Day JC, Bentall RP, Roberts C, Randall F, Rogers A, Catell D (2005) Attitudes toward antipsychotic medication: the impact of clinical variables and relationships with health professionals. Arch Gen Psychiatry 62(7):717-724

27. El-Gabry DM, Abdel Aziz K, Okasha T, Azzam H, Okasha A (2018) Antipsychotic polypharmacy and its relation to metabolic syndrome in patients with schizophrenia: an Egyptian Study. J Clin Psychopharmacol 38(1):27-33

28. El-Gabry DM, Ghanem M, Okasha T, Azzam H, Okasha A. Antipsychotic polypharmacy versus monotherpy and its metabolic side effects [M.D. Thesis]. Faculty of Medicine, Ain Shams University; 2013.

29. Loza N, Sorour E (2016) Brain drain: the issues raised for Egypt by the emigration of psychiatrists. B J Psych Int 13(3):59-61

30. Kendall T (2011) The rise and fall of the atypical antipsychotics. Br J Psychiatry 199(4):266-268

31. Geddes J, Freemantle N, Harrison P, Bebbington P (2000) Atypical antipsychotics in the treatment of schizophrenia: systematic overview and meta-regression analysis. Br Med J 321:1371-1376

32. Lieberman JA, Stroup TS, McEvoy JP, Swartz MS, Rosenheck RA, Perkins DO (2005) Effectiveness of antipsychotic drugs in patients with chronic schizophrenia. N Engl J Med 353:1209-1223

33. Jones PB, Barnes TRE, Davies L, Dunn G et al (2006) Controlled trial of the effect on quality of life of second- vs first-generation antipsychotic drugs in schizophrenia: Cost Utility of the Latest Antipsychotic drugs in Schizophrenia Study (CUtLASS 1). Arch Gen Psychiatry 63:1079-1087
34. National Institute for Clinical Excellence (NICE). Psychosis and schizophrenia in adults: treatment and management, 2014 (available at www.nice.org.uk/ guidance/cg178/resources/guidance-psychosis-and-schizophrenia-in-adultstreatment-and-management-pdf, Accessed 19 Mar 2018).

35. Taylor D, Paton C, Kerwin R (2015) The Maudsley Prescribing Guidelines $12^{\text {th }}$ edition. Martin Dunitz, London

36. Grover S, Avasthi A (2010) Antipsychotic prescription pattern. A preliminary survey of psychiatrists in India. Indian J Psychiatry 52(3):257-259

37. Varghese ST (2007) Antipsychotic drug prescription in postgraduate psychiatry training programs in India: time to reflect. Indian J Psychiatry 49:225

38. Haddad PM (2011) Medication cost and antipsychotic prescription. J Pak Psychiatr Soc 8(2):47-49

39. Dayalu P, Chou KL (2008) Antipsychotic-induced extrapyramidal symptoms and their management. Expert Opin Pharmacother 9:1451-1462

40. Taylor D, Paton C, Kerwin R (2003) The Maudsley Prescribing Guidelines $7^{\text {th }}$ edition. Martin Dunitz, London

41. Wu RW (2001) The combination of antipsychotics and anticholinergic medication. Chin Clin Doct 29:33-34

42. Xiang YT, Weng YZ, Leung CM, Tang WK, Ungvari GS (2007) Exploring the clinical and social determinants of prescribing anticholinergic medication for Chinese patients with schizophrenia. Hum Psychopharmacol 22:173-180

43. Sim K, Su HC, Fujii SY, Tang WK, Ungvari GS (2009) High-dose antipsychotic use in schizophrenia: a comparison between the 2001 and 2004 Research on East Asia Psychotropic Prescription (REAP) Studies. Br J Clin Pharmacol 67(1):110-117

44. Seeman P (2002) Atypical antipsychotics: mechanism of action. Can J Psychiatry 47(1):27-38

45. Wheeler J (2008) Treatment pathway and patterns of clozapine prescribing for schizophrenia in New Zealand. Ann Pharmacother 42(6):852-860

46. Gjerden P, Slordal L, Bramness JG (2009) The use of antipsychotic and anticholinergic antiparkinson drugs in Norway after the withdrawal of orphenadrine. Br J Clin Pharmacol 68(2):238-242

47. Hong IS, Bishop JR (2010) Anticholinergic use in children and adolescents after initiation of antipsychotic therapy. Ann Pharmacother 44(7):1171-1180

48. Bergman H, Soares-Weiser K (2018) Anticholinergic medication for antipsychotic-induced tardive dyskinesia. Cochrane Database Syst Rev 17(1): CD000204

49. Carriere I, Fourrier-Reglat A, Dartigues JF, Tang WK, Ungvari GS (2009) Drugs with anticholinergic properties, cognitive decline, and dementia in an elderly general population: the 3-city study. Arch Intern Med 169(14):1317-1324

50. Cancelli I, Gigli GL, Piani A, Zanchellin B, Janes F, Rinaldi A (2008) Drugs with anticholinergic properties as a risk factor for cognitive impairment in elderly people: a population-based study. J Clin Psychopharmacol 28(6):654-659

51. Rehse M, Bartolovic M, Baum K, Richter D, Weisbrod M, Roesch-Ely D. Influence of antipsychotic and anticholinergic loads on cognitive functions in patients with schizophrenia. Schizophr Res Treatment 2016; (available at https:/www.hindawi.com/journals/schizort/2016/8213165/Accessed 29 Apr 2018).

52. Land W, Pinsky D, Salzman C (1991) Abuse and misuse of anticholinergic medications. Hosp Community Psychiatry 42:580-581

53. Citrome $L$ (2009) Adding lithium or anticonvulsants to antipsychotics for the treatment of schizophrenia: useful strategy or exercise in futility. J Clin Psychiatry 70:932-933

54. Luchins DL (1984) Carbamazepine in violent non-epileptic schizophrenics. Psychopharmacol Bull 20:569-571

55. Leucht S, Helfer B, Dold M, Kissling W, MC Grath JJ. (2015) Lithium for schizophrenia. Cochrane Database Syst Rev 10:CD003834

56. Leucht S, Helfer B, Dold M, Kissling W, McGrath JJ (2014) Carbamazepine for schizophrenia. Cochrane Database Syst Rev 5:CD001258

57. Casey DE, Daniel DG, Tamminga C et al (2009) ER combined with olanzapine or risperidone for treatment of acute exacerbations of schizophrenia. Neuropsychopharmacol 34:1330-1338

\section{Publisher's Note}

Springer Nature remains neutral with regard to jurisdictional claims in published maps and institutional affiliations. 